\title{
Amphetamine-type stimulant use and conditional paths of consumption: data from the Second Brazilian National Alcohol and Drugs Survey
}

\author{
Luciana T.S. Massaro, ${ }^{1,2}$ Renata R. Abdalla, ${ }^{1,2}$ Ronaldo Laranjeira, ${ }^{1,2}$ Raul Caetano, ${ }^{3}$ Ilana Pinsky, ${ }^{1}$ \\ Clarice S. Madruga ${ }^{1,2}$ \\ ${ }^{1}$ Instituto Nacional de Ciência e Tecnologia para Políticas Públicas do Álcool e Outras Drogas (INPAD), São Paulo, SP, Brazil. ${ }^{2}$ Departamento \\ de Psiquiatria, Universidade Federal de São Paulo (UNIFESP), São Paulo, SP, Brazil. ${ }^{3}$ Prevention Research Center, Oakland, CA, \\ United States.
}

\begin{abstract}
Objective: The aim of this study was to estimate nationally representative prevalence rates of amphetaminetype stimulant (ATS) use and to identify consumption-associated factors, proposing a conditional model of direct and indirect consumption paths.

Method: Using data from the Second Brazilian National Alcohol and Drugs Survey, this cross-sectional study analyzed a subsample of 3,828 participants between 15 and 64 years old, gathering information on the use of psychoactive substances in a probabilistic sample of the Brazilian household population.

Results: Rates of lifetime and last-year ATS use were, respectively, 4.1 and $1.6 \%$. Economically privileged individuals and users of other substances were more at risk for using ATS. The results suggest that higher education decreases the chances of ATS consumption. The conditional model showed that higher income increased ATS use, higher education lowered the odds of such an increase, and cocaine use cancelled that associative effect.

Conclusion: Brazil presents high rates of ATS use. Prevention and treatment strategies should focus on the protective effect of higher education levels and should target polydrug use. Knowledge of ATSassociated factors and user profiles is the starting point for developing effective treatments and tailored prevention strategies.
\end{abstract}

Keywords: Amphetamine-type stimulants; moderation model; epidemiology; prevalence; Brazil

\section{Introduction}

Amphetamine-type stimulants (ATS) are a group of synthetic drugs that includes amphetamine and methamphetamine, as well as other substances, such as cathinones, methcathinone, fenethylline, ephedrine, pseudoephedrine, methylphenidate, and 3,4-methylenedioxymethamphetamine (MDMA, or "ecstasy"), some of which are legally produced, purchased, and used. ${ }^{1}$ The global proliferation of new synthetic drugs, also known as new psychoactive substances (NPS) is challenging pre-established mechanisms of access and policy $_{\text {control. }}{ }^{2}$ It is worrisome how fast and easily these new substances are being designed and produced, placing the recreational drug industry a step ahead of judicial authorities and drug control agencies. ${ }^{3}$

Recent reports indicate ATS usage rates of 0.5 and $0.6 \%$ in Europe and North America, respectively. ${ }^{4,5}$ Data on ATS consumption in Latin America are scarce, deriving mostly from police arrest reports, which are usually inaccurate. Nevertheless, according to the most recent

Correspondence: Clarice S. Madruga, Universidade Federal de São Paulo, Departamento de Psiquiatria, Rua Borges Lagoa, 570/82, CEP 04038-000, São Paulo, SP, Brazil.

E-mail: clarice @ uniad.org.br

Submitted Dec 15 2015, accepted Feb 22 2017, Epub Jul 062017.
United Nations Office on Drugs and Crime (UNODC) Latin American ATS Assessment, this class of drugs is one of the most widely used in the region, second only to cannabis. ${ }^{1}$

To date, estimations of ATS consumption in Brazil have been limited to specific populations, such as students ${ }^{6,7}$ and professional drivers, ${ }^{8}$ with recent studies indicating increased consumption in these populations. ${ }^{8,9}$ Despite the large body of evidence showing the addictive and neurotoxic proprieties of most drugs belonging to the ATS class, ${ }^{10}$ the general perception of users is that these drugs are less harmful than others, and the damage to physical, mental, and social health ${ }^{2}$ is, therefore, frequently underestimated. ${ }^{10,11}$ Some of the health consequences of ATS use are sleep disorders, psychosis, paranoid hallucination, agitation, confusion, severe panic, anxiety, depression, irregular heartbeat, tremors, muscle cramps and decreased capacity to cope with changing ambient temperature (which may result in hypo- or hyperthermia), including the risk of death. ${ }^{2,4,10}$ Additionally, the negative cognitive effects of ATS have been the subject of recent studies. ${ }^{12}$ Worse still is the fact that ATS consumers are usually polydrug users,${ }^{11}$ thus increasing their health risks, such as sexual risk behaviors, which might lead to unfavorable outcomes. ${ }^{13}$ In addition, previous studies have shown that socioeconomic and demographic 
characteristics can also have an impact on ATS consumption, acting either as protective factors against or risk factors for drug use and the development of addiction. ${ }^{14}$ This class of drug is still expensive compared to other stimulants such as cocaine, ${ }^{15}$ which is generally more available and cheaper in Brazil, leading to a higher chance of concomitant use. Furthermore, it is expected that higher education would decrease the chance of illicit drug use. ${ }^{14}$ Taking into account this body of evidence, the aim of this study was to propose a conditional path model for estimating the direct effect of income on ATS use in the country, exploring the role that education level and cocaine use play in the indirect path of this relationship. The study also provides national rates and investigates factors associated with ATS use in the country. Knowledge of the paths leading to ATS use is crucial to the development of tailored prevention strategies and treatment policies. ${ }^{1,16}$

\section{Materials and methods}

\section{Sampling and procedures}

The Second Brazilian National Alcohol and Drugs Survey (BNADS II), conducted in 2012, used a multistage cluster sampling procedure to select 4,607 individuals aged 14 years old or older - including an oversample of 1,157 adolescents - from the Brazilian household population. Brazilian residents who do not speak Portuguese (e.g., in isolated tribes) and individuals with severe intellectual disability were excluded from the sample. The overall response rate was $77 \%$, with $79 \%$ in the oversample of adolescents. The BNADS II sampling ${ }^{17}$ involved four stages: the selection of 149 counties using probabilityproportional-to-size methods; the selection of 375 total census sectors from within those counties, also using probability-proportional-to-size methods; the selection of 8 households within each census sector by simple random sampling; and, finally, the selection of one member of each household to be interviewed by the next-birthday method. Trained interviewers conducted face-to-face interviews of approximately one hour in the home of the respondent, using a standardized questionnaire. Methodological improvements over the BNADS I were implemented to avoid the underreporting of illicit drug use and to expand the list of evaluated substances. In BNADS II, the questionnaire's illicit drug use section was completed in a separate room by the participant, who then returned it to the interviewer in a sealed envelope. That change confounds comparisons between the two measurements (2006 and 2012) of illicit drug use rates. Additional details regarding the methodology employed in the BNADS II are available elsewhere. ${ }^{18,19}$

\section{Measurements}

\section{Socioeconomic and demographic variables}

In the present study, we evaluated a subsample of individuals between 15 and 64 years of age $(n=3,828)$ to allow comparisons with other studies in the literature. Socioeconomic and demographic variables (sex, age, education level, marital status, and personal income) were analyzed. Rates were also estimated for the five major geographic regions of Brazil.

\section{Substance use assessment}

We assessed self-reported lifetime and past-year use of ATS-class substances. Within the ATS class, we included questions about amphetamine, crystal meth, methylphenidate, ecstasy and other MDMA-derivative use, as well as non-prescribed snorted methylphenidate (Ritalin). The decision to combine these substances into a single variable was made, in the first place, to allow national comparisons with the UNODC data, ${ }^{2}$ which combines these drugs into an ATS category, although a new class called NPS in under consideration, which would act as an umbrella category for all newly-developed drugs, whether stimulants or not.

We also assessed the self-reported lifetime and pastyear use of other substances, including alcohol, tobacco, cannabis, cocaine (snorted or smoked), hallucinogenic drugs (such as lysergic acid diethylamide and psilocybin mushrooms), anesthetic drugs (such as ketamine and gamma-hydroxybutyrate), and tranquilizers (benzodiazepines).

In order to guarantee confidentiality, the drug-related questions were not asked face-to-face but were answered in private by each participant and returned at the end of the interview in a sealed envelope, which was immediately sealed in a bag in front of the respondent. Alcohol use disorder was assessed according to DSM-5 criteria. ${ }^{20}$

\section{Control variables}

Multivariate models included sex, age, and education level as control variables. The conditional model included sex and age as control variables.

\section{Statistical analysis}

All descriptive and multivariate models were run in STATA version 13.0. ${ }^{21}$ Prevalence rates were estimated using data weighted to correct for unequal probabilities of sample selection, and a post-stratification weight was applied to correct for non-responses and to adjust both samples to known population distributions of demographic variables (education level, age, sex, and region), according to the 2010 Brazilian Census. ${ }^{22}$ Cross-tabulations were used in order to examine lifetime and last-year ATS consumption rates across different socioeconomic and demographic characteristics by sex. Prevalence rates of alcohol use disorder, cannabis use, cocaine use, and the use of other illicit substances were also estimated, both in the sample as a whole and among ATS users. An exploratory multivariate analysis was performed with linear and logistic regression models to assess the unconditional associations between ATS use and the outcomes of interest while controlling for other socioeconomic demographic factors.

The conditional analysis was performed using PROCESS macro, version 2.16 (processmacro.org) for SPSS version 21.0. PROCESS macro is a computational procedure that implements moderation or mediation analysis 
(or a combination of the two) in an integrated conditional process model (i.e., moderations). ${ }^{23}$ To test the moderation model as a hypothesis, we used the analytic method discussed by Preacher and Preacher et al., ${ }^{24,25}$ adopting an algorithm for conditional process analysis. ${ }^{23}$ The moderation effects were estimated in PROCESS macro using a maximum likelihood estimator. Bias-corrected bootstrapping confidence intervals with 10,000 bootstrap samples were used to test the null hypothesis (i.e., that the indirect effect of cocaine use on ATS use is not significant), which did not take sample weighting into account. When confidence intervals contained zero, the null hypothesis was accepted. ${ }^{26}$ All models were evaluated using multiple indices of model fit $^{27}$ : a non-significant chisquare statistic, comparative fit index values greater than 0.95 , and standardized root mean square residual values less than 0.08 .

\section{Results}

\section{Amphetamine-type stimulant use}

Lifetime ATS use was reported by $4.1 \%$ of the individuals in the sample $(4.5 \%$ of the women and $3.8 \%$ of the men), as shown in Table 1. The use of ATS in the last 12 months (last-year ATS use) was reported by $1.6 \%$ of the individuals in the sample $(2.2 \%$ of the women and $1.1 \%$ of the men). The prevalence of lifetime and last-year ATS use was lower among inhabitants of rural areas. The ATS use rates were significantly higher in the central-west region than in the four other major regions of Brazil (the north, northeast, southeast, and south), reaching 9.0 and $4.6 \%$ for lifetime and last-year use, respectively $(p<0.05$; Table 1).

\section{Preliminary analysis of factors associated with ATS use}

Our preliminary results showed a significant association between income and last-year ATS use, in which the chance of using ATS were approximately 5 times greater for individuals in the highest income bracket than for those in the lowest income bracket (Table 2). The preliminary multivariate analysis also identified that the higher the education level, the lower the risk of ATS use. Last-year ATS use was positively associated with the use of all other illicit substances. Users of ATS were 7.07 times more likely to use cannabis, 7.68 times more likely to use other illegal substances and 21.31 times more likely to use cocaine or crack than non-ATS users. There was no significant association between ATS use and alcohol use disorder.

\section{Path models for ATS consumption}

In the preliminary multivariate regression models, after adjustments for all other socioeconomic and demographic characteristics, illicit drug use, cannabis and cocaine use were associated with ATS use, whereas education level lowered the chances of such use. Among all possible combinations of direct and indirect effects of these variables with ATS use, the best goodness-of-fit was shown by cocaine use and education as concomitant moderators of the direct effect of income on ATS use. The predictive power of this model was estimated using $R^{2}$ methods to determine goodness-of-fit (i.e., the McFadden, Cox \& Snell, and Nagelkerke methods), ${ }^{28}$ resulting in satisfactory values of $0.138,0.019$, and 0.1466 , respectively. As shown in Figure 1, education level and cocaine use moderated the effect size of income on ATS use. In other words, the chance of using ATS significantly decreased with a high education level ( $\geqslant 13$ years of schooling). The conditional model analysis showed (Table 3 ) a significant odds reduction with education level for the two quartiles of years of schooling -9.5 years (effect, $0.0004 ; 95 \% \mathrm{Cl}$ $0.0002-0.0007$ ) and 19.5 years (effect, $0.0004 ; 95 \% \mathrm{Cl}$ $0.0002-0.0006)$ - provided the value of the second moderator (cocaine use) was 0 (null). However, when the second moderator value was 1 (concomitant cocaine use), the association with education level ceased to be significant. In other words, education level had no effect on the magnitude of the direct effect between income and ATS use when cocaine use was concurrent. All association models were adjusted for sex and age. The same model was not valid when cocaine use was replaced by cannabis use or other illicit drug use as possible moderators.

\section{Discussion}

The use of ATS is a new issue in Brazil and has yet to be fully investigated. Our results indicate that $1.6 \%$ of a representative sample of the Brazilian population had used at least one ATS in the last year. Given the population size, ${ }^{29}$ this suggests that 3 million Brazilians used ATS in the 12 months prior to the survey. This indicates an enormous drug market and a potentially heavy burden on Brazilian society. This prevalence surpasses the $1 \%$ reported for Latin America in the latest UNODC study. ${ }^{1}$ In fact, it is higher than the prevalence reported for all other Latin American countries (e.g., approximately 1.0\% for Costa Rica, $0.67 \%$ for Colombia, and $0.5 \%$ for Bolivia), as well as for most European countries, where the average consumption rate is $0.6 \%$. $^{2,30}$

The prevalence estimated in our study follows a trend detected in another survey conducted in Brazil, ${ }^{31,32}$ which demonstrated a twofold increase (from 0.3 to $0.7 \%$ ) in amphetamine consumption between 2001 and 2005. In fact, the UNODC recently issued a warning about the increased use of stimulants in low- and middle-income countries, which are considered the preferred targets of organized crime groups involved in the ATS trade. The increased demand for ATS in such countries is probably associated with their emerging economies and young populations. Ecstasy-related arrests are also on the rise in Brazil, accounting for $47 \%$ of all ATS-related arrests between 2008 and 2012 in South America, Central America, and the Caribbean. ${ }^{1}$

The high prevalence of ATS consumption among women should also be highlighted. Stimulant misuse among women has previously been studied in Brazil, ${ }^{33}$ and our estimations corroborate those of a 2009 survey of college students, which estimated that the rates of lifetime ATS 


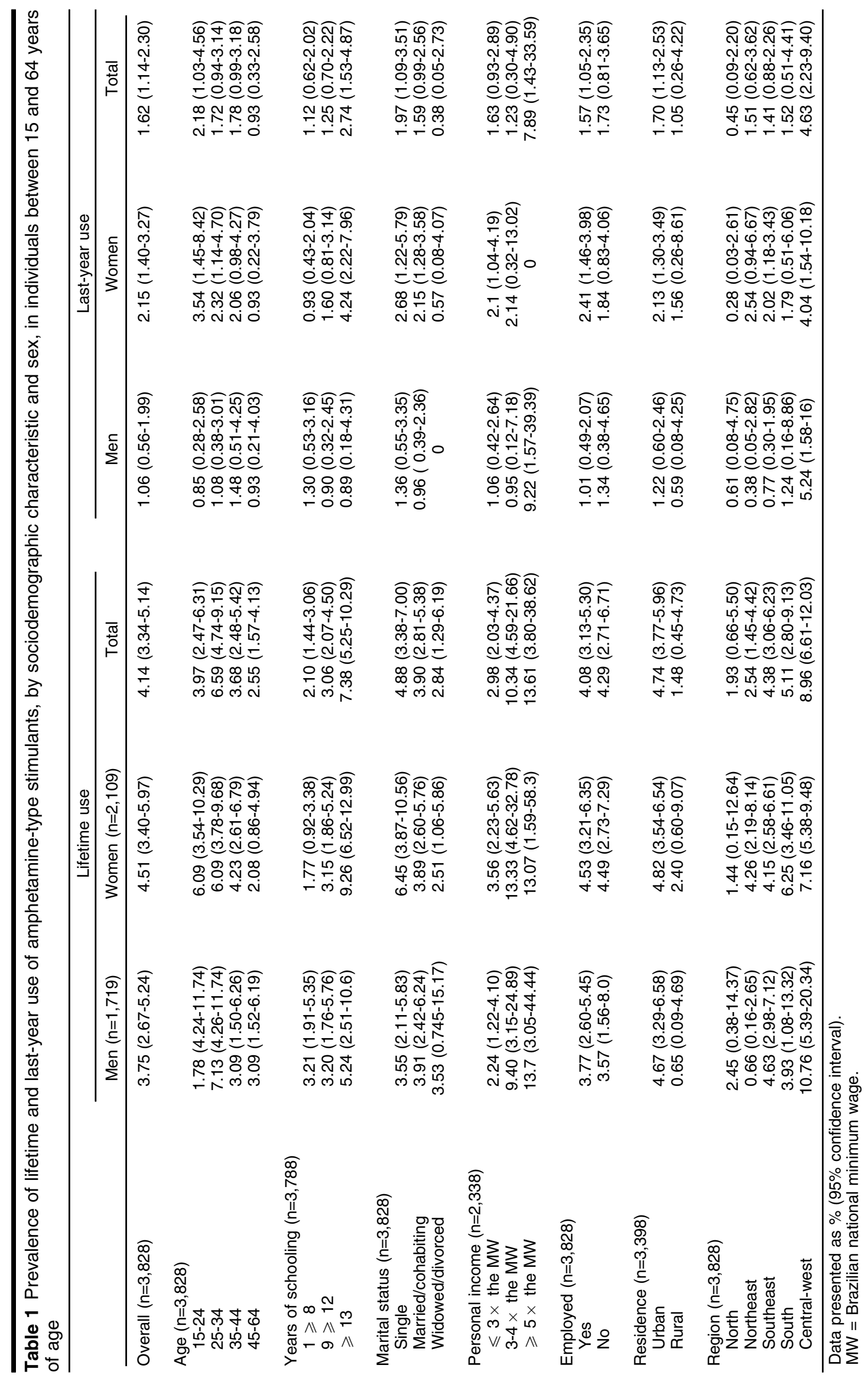


Table 2 Last-year use of amphetamine-type stimulants in relation to sociodemographic characteristics and the use of other substances*

\begin{tabular}{|c|c|c|}
\hline Independent variable & OR $(95 \% \mathrm{Cl})$ & $p$-value \\
\hline \multicolumn{3}{|l|}{ Sex } \\
\hline Male $(n=1,719)$ & 1.00 & \\
\hline Female $(n=2,109)$ & $1.90(0.71-5.10)$ & 0.202 \\
\hline \multicolumn{3}{|l|}{ Age $(n=3,828)$} \\
\hline $15-24$ & 1.00 & \\
\hline $25-34$ & $1.67(0.45-6.24)$ & 0.447 \\
\hline $35-44$ & $0.84(0.19-3.82)$ & 0.827 \\
\hline $45-64$ & $0.26(0.04-1.54)$ & 0.138 \\
\hline \multicolumn{3}{|l|}{ Years of schooling $(n=3,788)$} \\
\hline$\leqslant 8$ & 1.00 & \\
\hline $9-12$ & $0.48(0.16-1.43)$ & 0.187 \\
\hline$\geqslant 13$ & $0.26(0.07-0.99)$ & 0.003 \\
\hline \multicolumn{3}{|l|}{ Marital status $(n=3,828)$} \\
\hline Married/cohabiting & 1.00 & \\
\hline Single/widowed/divorced & $0.55(0.18-1.68)$ & 0.295 \\
\hline \multicolumn{3}{|l|}{ Personal income $(n=2,338)$} \\
\hline$\leqslant 3 \times$ the $\mathrm{MW}$ & 1.00 & \\
\hline $3-4 \times$ the $M W$ & $1.68(0.39-7.34)$ & 0.485 \\
\hline$\geqslant 5 \times$ the $\mathrm{MW}$ & $7.65(2.04-28.60)$ & 0.001 \\
\hline \multicolumn{3}{|l|}{ Work status $(n=3,828)$} \\
\hline Unemployed & 1.00 & \\
\hline Employed & $1.70(0.58-4.99)$ & 0.334 \\
\hline \multicolumn{3}{|l|}{ Residence $(n=3,398)$} \\
\hline Urban & 1.00 & \\
\hline Rural & $0.29(0.03-2.25)$ & 0.236 \\
\hline \multicolumn{3}{|l|}{ Other substance use } \\
\hline Alcohol abuse/dependence & $3.23(1.40-7.43)$ & 0.006 \\
\hline Cannabis use & 7.07 (2.46-20.31) & 0.000 \\
\hline Cocaine/crack use & $21.31(7.42-61.23)$ & 0.000 \\
\hline Other illicit drug use & $7.68(4.55-12.99)$ & 0.000 \\
\hline
\end{tabular}

$95 \% \mathrm{Cl}=95 \%$ confidence interval;

$\mathrm{MW}=$ Brazilian national minimum wage.

* Logistic regression models and sociodemographic variables were mutually adjusted for age, sex, and education level.

consumption were higher among women. ${ }^{7}$ The high prevalence of ATS use among women is a cause for concern, because it is known that heavy consumption patterns and symptoms of dependence are more rapidly established in women than men, and that the rates of relapse after one or more periods of abstinence are higher among women than men, ${ }^{34}$ which demonstrates the need for gender-specific support strategies. We also found significant associations between ATS use and the use of other substances, which is in agreement with a considerable body of evidence in the literature. ${ }^{35,36}$ Over a third of Brazilian college students reported using two or more substances in 2009, with amphetamine compounds among the most consumed substances. ${ }^{7}$ Although presenting large confidence intervals, our findings suggest that ATS users in Brazil are up to 21 times more likely to consume cocaine and almost 7 times more likely to use cannabis than individuals who do not use ATS. The strong association with cannabis is well documented, indicating an overlapping of user profiles. This can be attributed to user attempts to self-regulate the effects of ATS; cannabis acts mainly as a sedative, ${ }^{37}$ alleviating some of the undesirable effects of the stimulants. An association between ATS use and cocaine use has also been reported, due to similarities between user profile and use context. Above all, we highlight the association found between ATS use and socioeconomic status. Such a relationship has been identified in other studies conducted in Brazil ${ }^{7}$ and is supported by the fact that new synthetic stimulants are still relatively expensive in Brazil and other Latin American countries. Preliminary results from the Global Drug Survey 2015 showed that the average price of ecstasy in Brazil was €8.6 per pill and $€ 44.5$ per gram, ${ }^{15}$ confirming unofficial sources that one gram of MDMA can cost up to four times as much as the same amount of cocaine in Brazil. Our results corroborate this claim, showing that higher income increased the risk of ATS use. This was also confirmed by the conditional path model, in which this direct effect was moderated by cocaine use (whether snorted or smoked). The same relationship was not found with other illicit drugs, such as cannabis. The conditional model also showed that education level moderates the association between income and ATS use: each additional year of schooling reduces the direct effect between income and ATS use. However, when cocaine use was concomitant, the association with education level ceased (i.e., education level no longer decreased the chance of ATS use). Thus, cocaine use moderates the association between income and ATS use, magnifying the direct effect. This path analysis is quite self-explanatory, providing a clear insight into how such relationships can occur in a real-life context. Its interpretation leads to the conclusion that any attempts to prevent ATS use among risk groups should always embrace the prevention of other drug use and stress the harms of polydrug use. However, our results also indicate that a higher education level reduces the risk of ATS use in isolation (i.e., not combined with other stimulants). It is therefore imperative to promote the development of professional skills as protective measures against drug use. Initiatives aimed at prevention are efficient only when correctly targeted. ${ }^{38}$ Consequently, it is of the utmost importance to target the vulnerable groups identified in this study: young, affluent, poorly educated, polydrug users, and, in the specific case of ATS, women. The evidence presented here should help assess the impact that ATS use has on the mental health care system in Brazil, as well as provide a foundation for more efficient public health policies and strategies.

The intrinsic limitations of this study should be mentioned. First, we used a cross-sectional design, which demands a very careful interpretation of path analysis models to avoid assumptions about causal relationships. In addition, as in most assessments of illicit drug use, we must consider the possibility that drug use was underreported. Furthermore, we must emphasize that the variety of new synthetic stimulants is so broad that neither the participant's self-report nor even basic toxicology assessments could precisely detect which type of stimulants had actually been taken. To avoid misclassification, this study grouped any non-prescribed stimulant into a single category. 


\section{Conceptual model diagram}

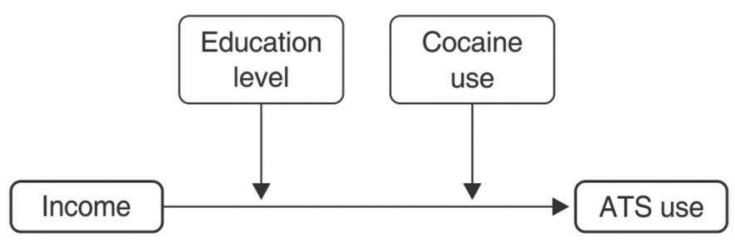

Statistical model diagram

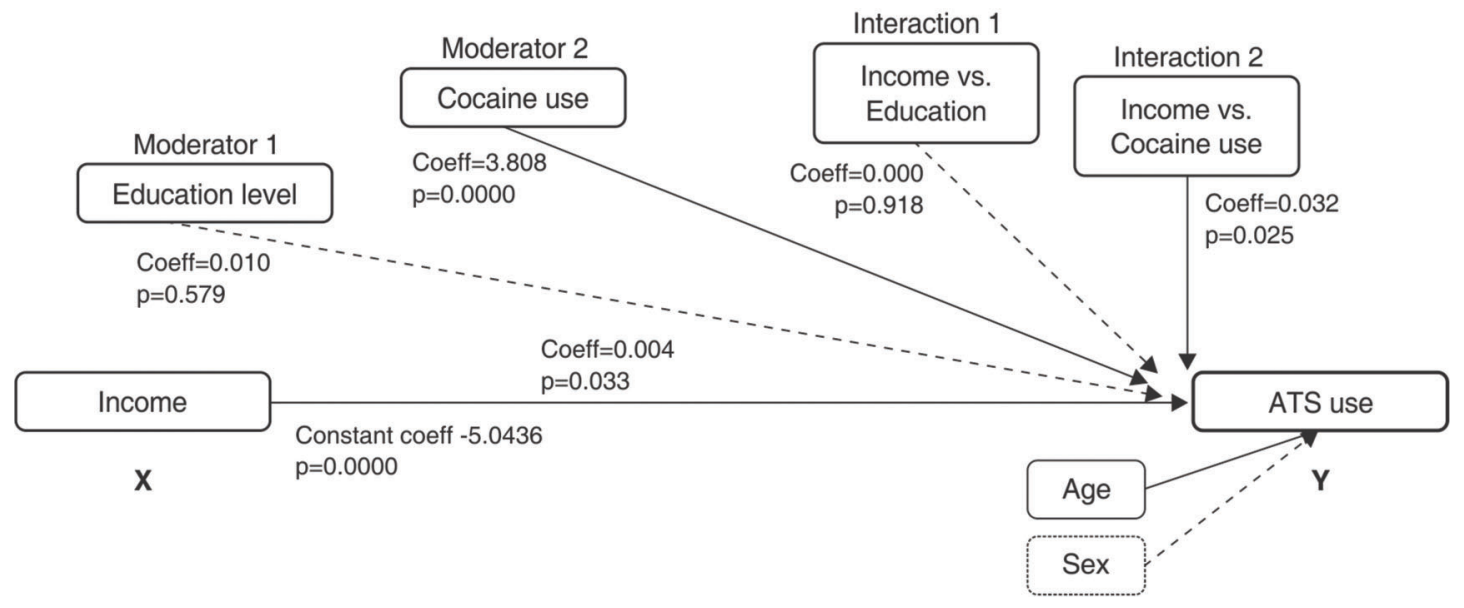

Figure 1 Conceptual and statistical diagrams illustrating the direct and indirect effects on amphetamine-type stimulant consumption.

Table 3 Conditional effect of income on amphetamine-type stimulant use at moderator values (years of schooling and cocaine use)

\begin{tabular}{lcccc}
\hline $\begin{array}{l}\text { Years of } \\
\text { schooling }\end{array}$ & $\begin{array}{c}\text { Cocaine } \\
\text { use }\end{array}$ & Effect & p-value & $95 \% \mathrm{Cl}$ \\
\hline 0 & 0 & -0.0004 & 0.033 & $0.000-0.0009$ \\
9.5 & 0 & -0.0004 & 0.006 & $0.0002-0.0007$ \\
19.5 & 0 & -0.0004 & 0.001 & $0.0002-0.0006$ \\
0 & 1 & 0.001 & -0.001 & $-0.003-0.0009$ \\
9.5 & 1 & 0.001 & -0.001 & $-0.003-0.0009$ \\
19.5 & 1 & 0.001 & -0.001 & $-0.003-0.0009$ \\
\hline
\end{tabular}

$95 \% \mathrm{Cl}=95 \%$ confidence interval.

This study represents a major investigation of ATS-use issues in a representative sample of the Brazilian population, one of the largest developing countries in the world. A cluster-like alignment of factors and events - a young population, an emerging economy, and a shortfall in mental health care and social services - has led to the rise of this foreseeable (and preventable) public health issue.

\section{Acknowledgements}

This study was supported by grants from Conselho Nacional de Desenvolvimento Científico e Tecnológico (CNPq) during the survey design and implementation and from Coordenação de Aperfeiçoamento de Pessoal de Nível Superior (CAPES) during the data analysis and interpretation stages.

\section{Disclosure}

The authors report no conflicts of interest.

\section{References}

1 United Nations Office on Drugs and Crime (UNODC). Amphetaminetype stimulants in Latin America [Internet]. 2014 [cited 2017 Mar 10]. www.cicad.oas.org/Smart/Reports/1_ENG.pdf

2 United Nations Office on Drugs and Crime (UNODC). Global Synthetic Drugs Assessment: Amphetamine-type stimulants and new psycoactive substances [Internet]. May 2014 [cited 2017 Mar 10]. unodc.org/documents/scientific/2014_Global_Synthetic_Drugs_ Assessment_web.pdf

3 Smith JP, Sutcliffe OB, Banks CE. An overview of recent developments in the analytical detection of new psychoactive substances (NPSs). Analyst. 2015;140:4932-48.

4 European Monitoring Centre for Drugs and Drug Addiction (EMCDDA). European Drug Report: Trends and Developments 2015 [Internet]. 2015 [cited 2017 Mar 10]. emcdda.europa.eu/attachements.cfm/att_239505_EN_TDAT15001ENN.pdf

5 United Nations Office on Drugs and Crime (UNODC). World Drug Report 2015 [Internet]. 2015 [cited 2017 Mar 10]. unodc.org/documents/wdr2015/World_Drug_Report_2015.pdf

6 Mendes SV, Troncoso LDy T, do Nascimento BS, Mühlbauer M. Estudo sobre o uso de drogas estimulantes entre estudantes de medicina. Cienc Atual. 2015;5:2-12.

7 Andrade AG, Duarte P, Oliveira LGd. I levantamento nacional sobre o uso de álcool, tabaco e outras drogas entre universitários das 27 capitais brasileiras. Brasília: Secretaria Nacional de Políticas sobre Drogas; 2010.

8 Oliveira LG, Endo LG, Sinagawa DM, Yonamine M, Munoz DR, Leyton V. [Persistent amphetamine consumption by truck drivers in São Paulo State, Brazil, despite the ban on production, prescription, and use]. Cad Saude Publica. 2013;29:1903-9. 
9 Wagner GA, Oliveira LG, Barroso LP, Nishimura R, Ishihara LM, Stempliuk Vd A, et al. Drug use in college students: a 13-year trend. Rev Saude Publica. 2012;46:497-504.

10 Schifano F, Corkery J, Naidoo V, Oyefeso A, Ghodse H. Overview of amphetamine-type stimulant mortality data--UK, 1997-2007. Neuropsychobiology. 2010;61:122-30.

11 Uosukainen $H$, Tacke U, Winstock AR. Self-reported prevalence of dependence of MDMA compared to cocaine, mephedrone and ketamine among a sample of recreational poly-drug users. Int J Drug Policy. 2015;26:78-83.

12 Sanvicente-Vieira B, Romani-Sponchiado A, Kluwe-Schiavon B, Brietzke E, Araujo RB, Grassi-Oliveira R. Theory of mind in substance users: a systematic minireview. Subst Use Misuse. 2017;52: 127-33.

13 Remy L, Narvaez J, Sordi A, Guimaraes LS, Von Diemen L, Surratt $\mathrm{H}$, et al. Correlates of unprotected sex in a sample of young club drug users. Clinics (Sao Paulo). 2013;68:1384-91.

14 Schenker M, Minayo MCS. Fatores de risco e de proteção para o uso de drogas na adolescência. Cienc Saude Coletiva. 2005;10: 707-17.

15 Global Drug Survey. Global drug survey 2015 findings [Internet]. 2015. globaldrugsurvey.com/the-global-drug-survey-2015-findings/

16 United Nations Office on Drugs and Crime (UNODC). World Drug Report 2013 [Internet]. 2013 [cited 2017 Mar 10]. unodc.org/doc/ wdr2013/World_Drug_Report_2013.pdf

17 Instituto Nacional de Ciência e Tecnologia para Políticas Públicas do Álcool e Outras Drogas (INPAD). II Levantamento Nacional de Álcool e Drogas [Internet]. 2012 [cited 2017 Mar 10]. http://inpad.org.br/ lenad/resultados/relatorio-final/

18 Madruga CS, Laranjeira R, Caetano R, Pinsky I, Zaleski M, Ferri CP. Use of licit and illicit substances among adolescents in Brazil -- a national survey. Addict Behav. 2012;37:1171-5.

19 Abdalla RR, Madruga CS, Ribeiro M, Pinsky I, Caetano R, Laranjeira R. Prevalence of cocaine use in Brazil: data from the II Brazilian national alcohol and drugs survey (BNADS). Addict Behav. 2014; 39:297-301.

20 American Psychiatric Association. Diagnostic and Statistical Manual of Mental Disorders, Fifth Edition (DSM-5). Arlington: American Psychiatric Publishing; 2013.

21 StataCorp. Stata statistical software.College Station: StataCorp LP; 2013.

22 Instituto Brasileiro de Geografia e Estatística (IBGE). Censo demográfico 2010: resultados gerais da amostra [Internet]. 2012 Apr 27. ibge.gov.br/home/presidencia/noticias/imprensa/ppts/000000084731 04122012315727483985.pdf

23 Hayes AF. Introduction to mediation, moderation, and conditional process analysis - a regression-based approach. New York: Guilford; 2015.
24 Preacher KJ. Multilevel SEM strategies for evaluating mediation in three-level data. Multivariate Behav Res. 2011;46:691-731.

25 Preacher KJ, Zhang Z, Zyphur MJ. Alternative methods for assessing mediation in multilevel data: the advantages of multilevel SEM. Struct Equ Modeling. 2011;18:161-82.

26 Edwards JR, Lambert LS. Methods for integrating moderation and mediation: a general analytical framework using moderated path analysis. Psychol Methods. 2007;12:1-22.

$27 \mathrm{Hu}$ Lt, Bentler PM. Cutoff criteria for fit indexes in covariance structure analysis: conventional criteria versus new alternatives. Struct Equ Modeling. 1999;6:1-55.

28 Allison PD. Measures of fit for logistic regression [Internet]. 2014 [cited 2017 Mar 10]. statisticalhorizons.com/wp-content/uploads/GOF ForLogisticRegression-Paper.pdf.

29 Instituto Brasileiro de Geografia e Estatística (IBGE). Pesquisa nacional de saúde 2013 [Internet]. 2013 [cited 2017 Mar 10]. ibge. gov.br/home/estatistica/populacao/pns/2013/

30 European Monitoring Centre for Drugs and Drug Addiction (EMCDDA). The state of the drugs problem in Europe. Annual Report 2012 [Internet]. 2012 [cited 2017 Mar 10]. emcdda.europa.eu/attachements.cfm/att_190854_EN_TDAC12001ENC_.pdf

31 Carlini EA, Galduróz JCF, Noto AR, Nappo SA. I Levantamento domiciliar sobre o uso de drogas psicotrópicas no Brasil: envolvendo as 107 maiores cidades do país - 2001 [Internet]. 2002 [cited 2017 Mar 10]. institutopaisefilhos.com.br/layout/apostilas/ILDomiciliarUso DrogasPsicotropicas.pdf

32 Carlini EA, Galduróz JC, Noto AR, Carlini CM, Oliveira LG, Nappo SA, et al. II Levantamento domiciliar sobre o uso de drogas psicotrópicas no Brasil: estudo envolvendo as 108 maiores cidades do país: 2005. Centro Brasileiro de Informação sobre Drogas Psicotrópicas (CEBRID): UNIFESP - Universidade Federal de São Paulo; 2007.

33 Wagner GA, Stempliuk Vde A, Zilberman ML, Barroso LP, Andrade AG. Alcohol and drug use among university students: gender differences. Rev Bras Psiquiatr. 2007;29:123-9.

34 Becker JB, Hu M. Sex differences in drug abuse. Front Neuroendocrinol. 2008;29:36-47.

35 Simons JS, Gaher RM, Correia CJ, Bush JA. Club drug use among college students. Addict Behav. 2005;30:1619-24.

36 Herbeck DM, Brecht ML, Lovinger K, Raihan A, Christou D, Sheaff P Poly-drug and marijuana use among adults who primarily used methamphetamine. J Psychoactive Drugs. 2013;45:132-40.

37 Davey J, Armstrong K, Martin P. Results of the Queensland 20072012 roadside drug testing program: the prevalence of three illicit drugs. Accid Anal Prev. 2014;65:11-7.

38 Escritório das Nações Unidas sobre Drogas e Crime (UNODC). Normas internacionais de prevenção do uso de drogas [Internet]. 2013. unodc.org/documents/lpo-brazil//noticias/2013/09/UNODC_ Normas Internacionais PREVENCAO portugues.pdf 